\title{
Multiobjective optimisation for improved management of flood risk
}

\author{
Michelle Woodward ${ }^{1}$, Ben Gouldby ${ }^{1}$, Zoran Kapelan² and \\ Dominic Hames ${ }^{1}$
}

${ }^{1}$ HR Wallingford, Howbery Park, Wallingford, Oxfordshire, OX10 8BA, UK

College of Engineering, Mathematics and Physical Sciences, University of Exeter, Harrison Building, North Park Road, Exeter, EX4 4QF, UK

Published in the Journal of Journal of Water Resources Planning and Management, May 2013

\section{Abstract}

Effective flood risk management requires consideration of a range of different mitigation measures.

Depending on the location, these could include structural or non-structural measures as well as maintenance regimes for existing levee systems. Risk analysis models are used to quantify the benefits, in terms of risk reduction, when introducing different measures; further investigation is required to identify the most appropriate solution to implement. Effective flood risk management decision making requires consideration of a range of performance criteria. Determining the better performing strategies, according to multiple criteria can be a challenge. This paper describes the development of a decision support system that couples a multiobjective optimisation algorithm with a flood risk analysis model and an automated cost model. The system has the ability to generate potential mitigation measures that are implemented at different points in time. It then optimises the performance of the mitigation measures against multiple criteria. The decision support system is applied to an area of the Thames Estuary and the results obtained demonstrate the benefits multiobjective optimisation can bring to flood risk management.

\section{Keywords}

Decision Support System, Floods, Multiple objective analysis, Algorithms, Optimisation, Decision Making

\section{Introduction}

It is widely recognised that flooding cannot reasonably be prevented and risk management approaches are often employed to minimise the likelihood of, and consequences associated with, extreme floods (Schanze, 2006, Samuels et al., 2009). To effectively manage flood risk it is often necessary to quantify the current risk and then assess a range of potential mitigation options. Mitigation measures can vary and may include standard maintenance activities of existing infrastructure, levee construction or refurbishment and flood proofing of properties. The option appraisal process aims to identify those that perform the best.

Performance is traditionally measured in terms of the economic costs of implementing a particular option and comparison with the benefits in terms of risk reduction, accrued over the lifetime of the project. Standard discounting procedures are typically used to derive the Net Present Value (NPV) of specific options. More recently however, it is becoming increasingly apparent that it is necessary to consider a wider range of performance metrics when considering flood protection infrastructure. More specifically, environmental impacts, business disruption costs, loss of life and amenity value, are all potentially important indicators of 
the value of flood risk mitigation measures to society and there is an increasing demand for these performance metrics to be formally considered as part of the appraisal process.

Flooding is a complex phenomenon, and the quantification of flood risk is challenging. This is particularly the case where flood protection infrastructure is present and it is necessary to consider the reliability of this infrastructure during extreme flood events. Floodplain protection often comprises static systems of levees that may operate in conjunction with mechanical flood gates, barriers or pumping stations, for example, in times of extreme flood. Hence, to quantify flood risk, it is necessary to model the whole system of infrastructure, rather than a single levee or flood gate for example, in isolation.

Risk analysis models that are capable of representing systems of floodplain and their associated flood protection infrastructure are now in widespread use, see for example, (USACE, 1996, Hall et al., 2003, Apel et al., 2004, Gouldby et al., 2008). In general, the models simulate a range of extreme flood events, consider a range of infrastructure failure states, as well as simulate the resulting flood inundation extents and consequences of flooding. The models can be used to quantify present day risk as well as identify benefits in terms of risk reduction, through implementing different mitigation measures.

Whilst these risk analysis models are capable of quantifying benefits associated with the risk mitigation options, they do not necessarily facilitate the selection of the best (most optimum) ones. They are currently not able to answer questions such as what are the best mitigation activities, and when would be the best time to implement them? This shortcoming arises as a result of the potentially vast decision space that requires consideration and its associated complexity. In any given floodplain system it is not unusual to have in excess of 100 different levee sections, as well as mechanical infrastructure (eg. pumps, gates and barriers). So, in principle, it is necessary to consider, for each element of the system, a number of different options; an increase or decrease in maintenance expenditure, refurbishment or complete replacement. Furthermore, mitigation measures are not restricted to the major flood protection infrastructure. Flood proofing of properties on the floodplain, for example, can also be a viable risk reduction measure and consideration of how many and which properties to fit also require assessment, in combination with the infrastructure measures.

Current approaches applied in practice typically use expert judgement based selection methods to reduce the options to a manageable number. These are then trialled at different specified future time steps within the appraisal period. Given the complexity of the problem and the subjective nature of the methods currently applied, this process is fallible. Advances in the scientific computational field have seen the development of a wide range of optimisation techniques that offer a more robust solution to this problem. For example, Lund (2002) uses a two-stage linear programming method and Voortman and Vrijling (2003) use a risk based design method to determine optimal flood defence systems. Voortman and Vrijling (2003) set a pre-defined requirement which ensures the flood system meets a pre-defined standard or flooding probability non exceedance. With this constraint, the problem solved is the minimisation of whole life construction costs. In the approach adopted in this paper, predefined limits are not set in advance. Instead the method seeks to optimise discounted benefits and costs simultaneously according to multiple criteria. Furthermore, in these previous approaches, simplifications have been made with regard to the risk analysis models used. These approaches assign probabilities to the range of flooding scenarios and consider damages that would be a consequence of a range of probability weighted flood events. The risk analysis method used herein uses a more comprehensive approach, taking into account a range of failure and non failure states of the flood system whilst considering multiple extreme hydraulic loading scenarios with varying severity.

In addition to the optimisation methods described above, there are a wide range of automated searching routines that are available, including many evolutionary based optimisation techniques, see for example the 
Genetic Algorithm (GA) (Goldberg, 1989), the Shuffled Complex Evolution Algorithm (Duan et al., 1993) and the Non-dominated Sorting Genetic Algorithm II (NSGAII) (Deb et al., 2000). Evolutionary algorithms are particularly useful in problems with many decision variables and as a result are widely applied. The algorithms evolve the solutions at each iteration, improving and learning from the previous set. In addition, multiobjective evolutionary algorithms provide a platform to consider numerous performance metrics without applying preferences to the criteria in advance.

One of the drawbacks of using evolutionary algorithms is the large number of model simulations that are required (often thousands) that can be prohibitive with regard to the runtime of simulation models. It is of note however, that the evolutionary algorithms do not necessarily need models that accurately quantify the performance metric. They require models that are sufficiently robust to accurately distinguish whether one solution is better than another. This property means computationally intensive models can, in principle, be simplified to reduce the computational burden associated with applying these algorithms.

This paper describes the application of a multi-objective optimisation algorithm to determine an optimum flood risk mitigation strategy for a flood protection system. The new methodology is tested and verified on a flood area located in London (UK), on the Thames Estuary. In order to reduce the computational runtime of the algorithm, a widely used system risk analysis model has been simplified. The paper describes the simplified system flood risk analysis method and explains why this is appropriate in the context of the application here.

\section{Background}

\section{Flood Risk Analysis}

Within the analysis described below, flood risk is calculated using a systems approach which has been applied to support the development of a long term flood risk intervention strategy on the Thames Estuary and the UK Environment Agency's National Flood Risk Assessment (Gouldby et al., 2008). Risk is expressed as the Expected Annual Damage (EAD) and requires consideration of a number of aspects. More specifically the probability of extreme flood events is represented through probability distributions that describe the probability of exceeding specified water levels within the outer estuary. The performance of the flood defence infrastructure, propagation of water across the floodplain and the consequences of flooding are defined in terms of economic damage to property and number of people affected.

The model considers a system of flood protection infrastructure protecting the floodplain. The floodplain is divided into a series of impact zones and further divided into impact cells (see Figure 1). The hydraulic loading conditions, (water levels, for example) are represented as continuous random variables acting upon the system of levee reaches. Each levee reach is assumed to have two possible system states, either remaining intact or breached (structurally failed), during a flood event. Their performance is defined by fragility curves. The fragility curves define failure probabilities conditional on the hydraulic loading conditions. These are typically defined through judgement based approaches, or through analysis of Limit State Equations, that describe different potential failure mechanisms. Further description on the derivation of fragility curves is provided in (USACE, 1996, Vorogushyn et al., 2009, Simm et al., 2009, Schultz et al., 2010).

As each levee reach is assumed to have two possible system states, the risk $R$, defined in terms of EAD, is given by: 
$R=\int \sum_{i=1}^{2^{n}} P\left(d_{i} \mid l\right) f_{L}(l) g\left(d_{i}, l\right) d L$

where $n$ is the total number of levee reaches, $/$ is the hydraulic load at each levee, throughout the system, $f_{L}(I)$ is the probability density function of hydraulic load, $d$ is a specific levee system state and $i$ is the levee system state index. The function (g) represents the consequences of a single discrete flood event (defined in terms of a specific hydraulic loading level and a levee system state).

In practice, $n$ can be large $(>100)$ and hence the number of possible levee system states is significant $\left(>2^{100}\right)$. It is therefore not practical, in terms of computational time, to undertake flood simulations for all levee system states. A Monte Carlo procedure is used instead to evaluate the distribution of flood damage, conditional on hydraulic load. The mean economic damage of this conditional distribution is as follows:

$\bar{z}_{l}=\sum_{i=1}^{2^{n}} P\left(d_{i} \mid l\right) g\left(d_{i}, l\right) \approx \frac{1}{m_{l}} \sum_{k=1}^{m_{l}} g\left(d_{k}^{*}, l\right)$

Where $d_{k}^{*}$ is sampled from the probability distribution of the defence system states for a given load such that $d_{k}^{*} \sim P\left(d_{i} \mid l\right), m_{l}$ is the total number of Monte Carlo samples undertaken for a specific hydraulic loading level $(I), i$ is the index across all levee system states and $k$ is the index denoting the sampled levee system state. The risk $R$ can now be computed as:

$R=\int f_{L}(l) \bar{z}_{l} d L$

The derivation of the joint density of the hydraulic loads can be complex to define over large spatial areas and involve further Monte Carlo simulation to solve the associated integral (Hawkes et al., 2002, Lamb et al., 2010). In practice, an assumption is therefore often made that hydraulic loading conditions are fully dependent in terms of recurrence interval (return period) within a flood area. This enables the integration of the joint density of the hydraulic loads over the consequence function to be undertaken in terms of a single probability of hydraulic load (Hall et al., 2003; Gouldby et al., 2008). This means a computationally more efficient integration procedure can be applied, whereby the continuous extreme value probability distributions for the hydraulic loads are discretised into a series of $q$ levels (denoted below using the subscript $j$ ) and thus the risk is now defined as:

$R \approx \sum_{j=2}^{q-1} P\left(\frac{l_{j-1}+l_{j}}{2}<L \leq \frac{l_{j}+l_{j+1}}{2}\right) \bar{z}_{l_{j}}$

Where $L$ is a random variable of hydraulic load, $P$ is the probability of $L$ occurring, and $j$ is the index denoting discretised loading levels.

For the purposes of optimisation, equation (4) has been further approximated to reduce the computational burden. This approximation is described below in the simplification of the flood risk model section. Figure 4 illustrates the main processes involved within the risk analysis tool, with the specific steps in the analysis outlined. 


\section{Multi-objective optimisation}

Good flood risk management decisions consider a range of performance indicators. Some multi-criteria decision making methods that incorporate optimisation advocate converting multiple objectives into a single criterion producing only one optimal solution (Deb et al., 2002). There are many single objective optimisation techniques available which are straight forward to implement for this purpose, with the GA being a popular well established evolutionary method (Goldberg, 1989). To implement these methods however, it is often necessary for decision makers to weight the criteria into a single objective which can be controversial, particularly with regard to assigning weights (Coello, 1999). Single objective optimisation also results in a single best solution which does not necessarily provide a comprehensive view of the solution space and can therefore potentially distort the decision making process.

Multi-objective optimisation methods optimise all conflicting objectives simultaneously, whilst keeping them in their native metric. For example, loss of life can be expressed as number of people and optimised against the cost of an intervention which is expressed in monetary terms. The aim of evolutionary multi-objective optimisation is not to identify the single best solution but to provide a set of trade off solutions. This set of solutions is known as the Pareto-optimal set, see Fonseca and Fleming (1998) for an extensive discussion of this topic. This allows a range of possible solutions to be considered and provides decision makers with a greater insight into the potential trade-offs between the objectives. Whilst also providing decision makers with additional information, there can be difficulties interpreting the information, when the number of objectives increases above three and research has been undertaken to address this problem, see (Valdes and Barton, 2007), for example.

Evolutionary algorithms are based on natural evolution to solve optimisation problems, for a detailed explanation see (Goldberg, 1989, Coello, 1999). In summary, a set of potential solutions to the problem are generated. Each solution is individually evaluated and a fitness value is assigned according to its performance against the objectives. Based on the initial set of solutions and their fitness values, a new population of solutions is generated. This new population consists of high performing solutions from the previous set and modified solutions by means of crossover and mutation operators. This new population is evaluated and assigned a fitness value before the next population is formed. This process is repeated until there can be no improvement to the solutions, i.e. the optimal solutions have been found.

There is an extensive range of evolutionary algorithms which follow the fundamental steps above but often differ in their methods to support the inclusion of Pareto optimality. See for example the Non-Dominated Sorting Genetic Algorithm II (Deb et al., 2000), the SPEA2 (Zitzler et al., 2001) and the عMOEA (Deb et al., 2003) Evolutionary algorithms such as these have been applied to water resources problems for many years to aid the decision making process, see for example (Savic and Walters, 1997, Kapelan et al., 2003, Behzadian et al., 2009, Dorini et al., 2010, Weickgenannt et al., 2010). However as of yet, despite the obvious advantages, multiobjective optimisation has not been applied to flood risk management problems that include the likelihood of failure of the flood protection systems.

\section{Flood Risk Management Methodology}

This paper introduces multi-objective optimisation into flood risk management decision making to determine optimum mitigation strategies. An explanation is provided below of the methodology including the problem formulation, a simplified system risk analysis model and a cost model. 


\section{Optimisation Problem}

The problem description involves the identification of better performing combinations of intervention measures according to a set of criteria. For the purpose of this paper, for each levee section, two interventions are considered namely, structural interventions, $X_{s}$ (raising the height of levees and refurbishment) and maintenance activities, $X_{m}$. The optimisation problem in this paper is to find an intervention strategy or vector $X=\left(X_{s}, X_{m}\right)=\left(x_{s_{1}}, x_{s_{2}}, \ldots, x_{s_{n}}, x_{m_{1}}, x_{m_{2}}, \ldots, x_{m_{n}}\right)$ which optimises $f(x)=[B(x), C(x), \operatorname{Li}(x)]$, where $\mathrm{B}$ is the benefits associated to implementing the intervention strategy, $\mathrm{C}$ is the costs of the intervention strategy and $\mathrm{Li}$ is the loss of life, these variables are described in more detail below. The optimisation looks to maximise $B(x)$ and minimise $C(x)$ and $L i(x)$.

The benefits of an intervention strategy are obtained using the risk analysis tool described earlier in the paper under the flood risk analysis section. The risk, $R$, in terms of EAD, at any particular point in time is obtained from equation (1). Let the risk of a given intervention strategy at any point in time be a function of the intervention measures, the extreme flood events, $I$, and the performance of the levee infrastructure $X_{p}$ such that $R=g_{1}\left(X_{s}, X_{m}, I, X_{p}\right)$. The benefits in terms of risk reduction, $B$, for an intervention strategy can therefore be evaluated as the difference in EAD at each point in time from an option where interventions are implemented and a do nothing option where no interventions occur such that:

$$
B=\sum_{t=1}^{T} \frac{g_{1}\left(X_{s}, X_{m}, l, X_{p}\right)_{t}-g_{1}\left(l, X_{p}\right)_{t}}{(1+r)^{t}}
$$

where $T$ is the total number of future epochs considered in an intervention strategy, $t$ represents the epoch index and $r$ is the discount rate. The cost, $C_{T}$, at any particular point in time of an intervention strategy is a function of the intervention measures implemented such that $C_{T}=g_{2}\left(X_{s}, X_{m}\right)$. Section 3.3 provides further details on the calculation of the costs. The total cost, $\mathrm{C}$, is calculated across all epochs as:

$C=\sum_{t=1}^{T} \frac{g_{2}\left(X_{s}, X_{m}\right)_{t}}{(1+r)^{t}}$

In addition to economic risk reduction and costs, intervention strategies are also evaluated according to the effect on people and their properties. Whilst there are complex models for analysing life-loss from flooding, (Lumbroso et al., 2008, Aboelata and Bowles, 2010), a simplified approach has been applied here to demonstrate the concepts and principles of the multi-objective optimisation approach. The simple surrogate for loss of life, $L i$, calculates the annual probability of exceeding a flood depth $y$ in a given impact zone and multiplies this by the number of properties in that zone. This is summed across all impact zones in the floodplain to give:

$L i=\sum_{k=1}^{K} P(Y>y) N_{k}$

Where $N$ is the number of properties in an impact zone, $K$ is the total number of impact zones in the floodplain and $k$ represents the impact zone index. 
The decision variables, $X_{s}$ and $X_{m}$, are vectors which represent the specific intervention to apply to each of the levee reaches, $d$, in the flood system such that $X_{s}=\left(x_{s_{1}}, x_{s_{2}}, \ldots, x_{s_{\alpha}}\right)$ and $X_{m}=\left(x_{m_{1}}, x_{m_{2}}, \ldots, x_{m_{\alpha}}\right)$ where $\alpha$ equals the total number of reaches in the flood system. Structural interventions, $X_{s}$ such as raising the height of a levee can take a range of discrete heights, increasing from $0 \mathrm{~m}$ to $2 \mathrm{~m}$ at $0.33 \mathrm{~m}$ intervals. The decision variable $X_{m}$ can take the value of four possible maintenance options including no maintenance, low, medium and high. These maintenance scenarios are reflected through the use of deterioration rates (Environment Agency, 2009b) which express the time in years to deteriorate from one condition grade to another. Condition grades represent the deterioration within the risk analysis model explained in section 2.1 and change according to the rate of deterioration.

\section{Optimisation Method}

The Non-dominated Sorting Genetic Algorithm II (NSGAII) is used to solve the aforementioned problem (Deb et al., 2000). The NSGAll is an evolutionary multi-objective optimisation technique which is based on the process involved in a GA and builds upon the foundations of the NSGA developed by Srinivas and Deb (1994). Like the GA, the NSGAll is also based on Darwin's theory of natural selection and survival of the fittest but there are also some differences between the NSGAll and the single objective GA to support multiobjective optimisation. Solutions are evaluated simultaneously according to multiple criteria; this alters the mechanisms required for the fitness and selection processes. Unlike the fitness calculations for the single objective GA, the NSGAll has additional layers of classification for each individual solution. For example, before the selection operator occurs, the solutions are ranked according to non-domination and assigned a crowding distance to determine its fitness. The main stages of the NSGAll are described in the algorithm in Figure 2.

\section{Simplified Flood Risk Assessment Method}

The hydraulic aspects of the risk analysis model, comprise use of the well known weir equation and associated flood duration to calculate volumes discharged into the floodplain. For every hydraulic loading level $(I)$, a volume discharged into the floodplain is calculated under the assumption that the levee reach has breached or remained intact but overtopped. Within the full risk analysis model, for every loading level, the levee system states are sampled through a Monte Carlo procedure. For every levee system state sample, there is a volume associated with each reach. This volume is discharged into the floodplain where a computationally efficient flood spreading model (Rapid Flood Spreading Model (RFSM)), distributes the volume of water over the floodplain area. Full details of this analysis are provided in (Gouldby et al., 2008), further information on the RFSM is provided in (Lhomme et al., 2008).

The levee system state Monte Carlo procedure can take between fifty and several thousand simulations to converge, for any given hydraulic loading level. Even though the RFSM is computationally efficient, it still takes a significant amount of time to undertake this type of analysis for the many 1000's of simulations required for the optimisation algorithm.

To further reduce the computational burden the Monte Carlo simulation has been approximated and replaced with an approach that uses the expected volume that is discharged into the floodplain at each loading level. More specifically, the expected total volume that is discharged into the floodplain, conditional on loading level $(I)$, is defined as: 
$E\left(\bar{v}_{l}\right)=\sum_{i=1}^{n} p\left(d_{i}\right) v_{i}+p\left(\bar{d}_{i}\right) \bar{v}_{i}$

Where $p\left(\bar{d}_{i}\right)$ is the probability of structural failure (breaching) of a single levee reach and $p\left(d_{i}\right)$ is the probability of overtopping. The components $v$ and $\bar{v}$ are the flood volumes associated with the overtopped and failed levee reaches respectively.

This expected volume for each levee reach (each $i$ ) is discharged into the floodplain according to its spatial location. The volumes discharged into the floodplain are then distributed over the floodplain using the RFSM. The resulting economic damage is calculated as:

$\bar{z}_{l} \approx g_{3}\left(E\left(\bar{v}_{l}\right)\right)$

Where $\left(g_{3}\right)$ is a function of the expected volume at a levee reach. Equation (9) is then substituted into equation (5) and used to estimate the risk:

$R \approx \sum_{j=2}^{q-1} P\left(\frac{l_{j-1}+l_{j}}{2}<L \leq \frac{l_{j}+l_{j+1}}{2}\right) g_{3}\left(E\left(\bar{v}_{l_{j}}\right)\right.$

The resolution at which the probability space associated with the hydraulic loading conditions is discretised (ie the number of $/$ levels) affects the model run time, and can significantly influence the results, (Ward et al., 2011). To further reduce the runtime for the purposes of optimisation analysis, the number of loading levels was also reviewed. On the case study described below it was found that the number of loading levels could be significantly reduced from the typical forty, that are used in current practice, to seven. An example of the change in the probability damage curve, that results when only seven levels are used is shown in Figure 3 . It should however, be noted that this approximation has only been verified on the case study site described below and further testing is required before this approximation could be accepted as a generalized approach for optimisation studies.

These approximations enable a significant improvement to the computational efficiency of the risk model. Rather than running a large number of flood simulations (approximately 2000) for every loading level, only one simulation of the RFSM is required. Additionally, the number of loading levels further improves the computational runtime. The approximation of the volume discharged into the floodplain does however influence the accuracy of the performance metric calculation. This is not necessarily of concern for the purposes of optimisation, if the change in accuracy is relative across solutions and the risk model maintains the relative order of better performing intervention strategies, i.e. the correct preference ordering. To confirm that the approximation implemented within the risk model is appropriate for optimisation, a comparison of the full risk model and the simplified version has been made.

The comparison uses the model of the Thames Estuary, described below. With this model an initial set of 500 flood risk mitigation intervention measures were randomly generated (ie changes to the configuration of the levee system, levee raising, for example) were made. The risk associated with each of the re-configured levee systems was then evaluated using both the full and simplified risk models. A sample of the results obtained are shown in Table 1.The bottom triangle in blue displays the EAD for 15 re-configured levee systems analysed using the full risk analysis model. A cross evaluation matrix of each levee system is shown to compare all possible combinations of levee systems identifying the best performing systems (i.e. the systems with lower EAD values). For each individual rank comparison, the best performing levee system is 
written in the matrix. The cross evaluation matrix for the full risk analysis shows that system 9 performs the best with no other system obtaining a lower EAD. Likewise, system 4 has the worst performance and was not able to outperform any other system.

The same re-configured levee systems were also evaluated using the simplified risk model and again compared in a cross evaluation matrix. The results obtained for the first 15 systems under the simplified risk model are shown in the top triangle in yellow in Table 1. If the simplified risk model is a suitable replacement to the full version then the order of better performing interventions should be approximately equal. As in the comparison of the full risk model, the simplified risk model identified system 9 to have the highest performance and system 4 to have the lowest.

From Table 1 it is evident that a similar identification of better performing systems is found in both triangles and thus across both versions of the risk analysis model, with only two cases which did not correspond.

From the full results of all 500 re-configured levee systems, $97.82 \%$ of the systems followed the same recognition of performance for both versions of the risk model thus suggesting the simplified version can replace the full version in this instance. This test was repeated for 5 different sets of 500 randomly generated re-configured levee systems to verify the results (see Table 2).

Each test further confirms that the simplified risk analysis model is a reasonable approximation for the full version and can be used for the purposes of optimisation without compromising results for the case study below. Across all 5 tests the average percentage of systems following the same performance is $97.97 \%$.

Figure 4 illustrates with two flowcharts the differences in the risk analysis model when applying the approximations explained above.

\section{Cost Estimation}

The approach to costing developed here identifies costs for 61 different defence classes used within the risk model which were formulated for the National Flood Risk Assessment of England, (Hall et al., 2003). The basis of the cost model extends the Cost Estimation Model given by Phillips (2008). The two main categories for the costing model here calculate the costs associated with structural interventions and levee maintenance. Figure 5 describes the main stages of the costing methodology. The costs associated with structural interventions, $C_{S}$, take into consideration the mobilisation $(M)$ and operating costs $\left(O_{D}\right)$, the quantity of work required $\left(Q_{j}\right)$ and the unit cost of materials $\left(W_{j}\right)$, as well as the number of maintenance and/or construction items $(m)$ :

$$
C_{s}=M+O_{D}+\sum_{j=1}^{m} Q_{j} W_{j}
$$

The quantity of work required is expressed using the characteristics of the levee such that

$$
Q_{j}=V_{D} D_{L} g_{4}\left(D_{x}, X_{s}, G\right)
$$

where $V_{D}$ are the levee dimensions, $D_{L}$ is the length of the levee that requires attention, $D_{x}$ is the severity of the defects which is a function of the condition grade (CG) of the levee, $X_{s}$ represents the intervention measures being applied and $G$ is the type of defence being modified. Figure 6 displays the flowchart to obtain the quantity of work and an example of the input data required. The total overhead and mobilisation costs are based on a combination of prices published in Langdon (2010) and expressed as: 
$M+O_{D}=\sum_{j=1}^{m} h_{j}\left(T_{w} U_{j}+M_{j}\right)+A$

where $h_{j}$ is the unit number of each mobilisation activity, $T_{w}$ is the number of weeks on site, $U_{j}$ is the unit cost of each overhead for each mobilisation activity, $M_{j}$ is the mobilisation and demobilisation cost for each activity, $A$ is the site access costs and $m$ is again the number of maintenance and construction items.

Maintenance costs, $\mathrm{C}_{\mathrm{m}}$, within the model support three levels of maintenance as well as a do nothing option. The three levels of maintenance: low, medium and high each correspond to a rate of deterioration. The rates used with in this model are obtained from the Environment Agency of England and Wales (2009b) with the associated costs also obtained from the Environment Agency (2009a). The total costs, $C_{T}$, for a given point in time is simply the maintenance costs plus the structural intervention costs:

$C_{T}=C_{s}+C_{m}$

\section{Case Study}

\section{Description}

The new methodology has been applied to a specific flood area that closely resembles a location on the Thames Estuary (London, UK), an estuarine area that without intervention measures is susceptible to flooding. A large scale flood event could have a devastating impact as it accommodates over a million residents and workers, 500,000 homes and 40,000 non-residential properties (Environment Agency, 2009c). The threat of flooding within the Thames Estuary occurs from a combination of different sources, including high sea levels and surges propagating down from the North Sea into the Estuary, and extreme fluvial flows along the Thames and its tributaries. Protection against these sources is provided by a range of fixed protection structures and actively operated barriers and flood gates. The majority of the levee reaches were designed to protect against a 1-in-1000 year flood however, the system is naturally degrading and there is a need to consider future maintenance and intervention measures (Environment Agency, 2009d).

The application of the modelling system focuses on an area resembling Thamesmead, located on the Estuary (see Figure 9). This area contains 79 Levee sections which have been classified into 5 groups according to their characteristics and location. The advantages of grouping levees are two-fold. Firstly, in practice it is often more realistic and economically efficient to apply intervention measures to a group of protection structures rather than individually and secondly, grouping levee reaches will reduce the computational effort required to solve the optimisation problem as there are fewer decision variables to consider.

A medium term (20 year period) flood risk management plan has been developed for these groups of levees where there is the opportunity to apply interventions at two ten year intervals. For simplicity, only two interventions of those described above are considered. The interventions considered are raising the levee height and selecting a level of maintenance. A larger range of intervention measures are however supported by the methodology and the concepts remain the same.

The analysis undertaken comprised two simulations. The first scenario considers two objectives, discounted costs and benefits; the second scenario includes the additional loss of life objective. 


\section{Results and Discussion}

Figure 7 displays the progression of the Pareto front as each generation is advanced by the evolutionary algorithm. Each point on the graph represents a flood risk intervention strategy, with the square points representing solutions in the Pareto front for that generation and the circular points representing the remaining solutions. The improvement of the solutions can be seen across the generations in Figure 7 with convergence on the Pareto optimal front by the final generation. To verify convergence, the optimisation simulation was rerun with a different random seed to produce a different initial population. As the GA is a stochastic search method the results obtained depend on the initial population which are randomly generated from the search space. Altering the random seed ensures each optimisation simulation will begin its search for an optimal solution from a different part of the search space. The final Pareto optimal front displayed in Figure 7 was reproduced when using a different seed verifying convergence. Additionally, optimal solutions have been identified along the front such as the least cost option (the 'do nothing' option) further verifying convergence.

The Pareto optimal front obtained in the final NSGA2 generation is displayed in Figure 8. As can be seen in Figure 8 , a solution cannot be improved according to one objective without causing a negative effect on the other objective. For example, improving the benefits will result in an increase in costs. The decisions can be determined according to specific target levels that must be met for each criterion, for example, a specific benefit that must be reached, or if there is a constraint on total expenditure allowed. Preferences and weightings can also be implemented to reduce the number of options available. Common performance measures to combine the benefits and costs include the NPV (difference between the discounted benefits and costs) and the BCR (ratio of the discounted benefits to costs); the maximum values of these have been identified in Figure 8 as the triangle point and square point respectively.

All the strategies in the Pareto Front of Figure 8 focus on intervention measures for levee groups 1 and 3 only. The remaining groups of levees do not have any height increases or maintenance levels suggested. To investigate the reasoning behind the selection of groups 1 and 3, Figure 9 displays a flood depth realisation for a loading event with a nominal 100 year Return Period. It can be seen that the majority of the flood water for this realisation centres around groups 1, 3 and 4. Group 3 is the largest group of levees and the majority of the flood water can be attributed to this group. The spread of flood water adjacent to groups 3 and 4 can be reduced if the levees in group 3 are maintained and prevented from breaching. Group 1 protects a highly developed area and flooding in these zones will increase the risk significantly. By providing maintenance to groups 1 and 3 the majority of the flood depths can be reduced confirming the choices of the NSGA2 to only apply maintenance to groups 1 and 3 .

Table 3 displays the information for the strategies with the highest NPV and BCR (B and C in Figure 8) and three additional strategies ( $A, D$ and $E$ in Figure 8). Comparing strategies $A$ and $B$, it can be seen that for a minimal increase in costs, the benefits can be significantly improved, favouring strategy $B$. Similarly comparing strategies $C$ and $D$ with $E$, the increase in benefits obtained from raising the crest levels of the levees in group 1 at the second time step does not outweigh the considerable increase in cost. The optimal solution produced from a single objective optimisation would select the strategy with either the highest NPV or BCR depending on the objective. No additional information would be provided including information on other potential strategies or by how much the optimum strategy is preferred.

It is important to provide decision makers with all the necessary information to ensure that the selected option is chosen with knowledge of all relevant information, as shown in Figure 8. The decision making process may result in the selection of a strategy with the highest NPV or BCR but it can be important to 
understand how this strategy fits in and compares to other potential solutions and ensure the best strategy is selected given the problem at hand. Multi-objective optimisation methods provide a means to present additional information to decision makers and offer additional insight into the problem, its characteristics and potential solutions, all of which is not typically available.

The analysis presented so far focuses on the economic performance of intervention strategies in terms of benefits and costs. The second simulation presents results when using a third objective, the loss of life. Figure 10 displays the Pareto Front of the final generation for each pair of objectives with each point on the graph representing a potential flood risk intervention strategy. Considering the benefits and costs, the typical trend sees an increase in costs to obtain an increase in benefits. Similarly, to decrease life loss a higher cost is required. Comparing loss of life against benefits, it can be seen that the higher the benefits the lower the number of lives at risk.

In Figure 10 the strategy with the highest NPV, represented using a triangular marker, and the strategy with the highest BCR, represented by a square, are the same strategies with the highest BCR and NPV in Figure 8 (strategies B and C in Table 3). In terms of benefits and costs the evolutionary algorithm has again found these and identified them as optimum solutions. Other strategies identified in Figure 8 have also been included in the Pareto front in Figure 10. However, when considering the third objective, optimum strategies according to benefits and costs are no longer optimum in terms of the loss of life surrogate. Most noticeably, the trade off between NPV and BCR against loss of life shows that these strategies are not preferable with respect to loss of life. Additional strategies have been included to the Pareto front in Figure 10 which do not exist in Figure 8 as they are optimum with regards to the loss of life surrogate but do not perform well against the cost objective.

As in the two-objective case, the interventions in the Pareto Front mainly suggest applying interventions to groups 1 and 3. To keep costs down, and also provide a reasonable benefit, applying maintenance regime to the two levee groups is sufficient. However, to satisfy the third objective, minimise loss of life, intervention strategies are required which also raise the crest levels of levees in groups 1 and 3 (see strategies A and E in Table 4). This will increase costs without much additional benefit in terms of flood risk reduction but a significant reduction in the number of properties which are still at risk will be seen thus resulting in reduced loss of life. This illustrates the importance of addressing the potential loss of life as a separate optimisation objective as it can be controversial, to put a value on human life.

\section{Conclusions}

This paper describes a new methodology and an associated decision support system to aid decision making in flood risk management. An existing risk analysis model has been simplified for use with optimisation algorithms that are computationally intensive. The simplified risk analysis methodology reduces the number of inundation model simulations required to estimate EAD from more than 40,000 , to 7 . The reduction in the number of inundation model simulations results in a significant decrease in the model runtime. The simplified model has been trialled on a case study site where it has shown to be appropriate for the purposes of optimisation. Further analysis is however, required to establish whether this conclusion is generic and the model can be applied to a wider range of locations.

The simplified risk analysis model has been coupled with a costing module and the NSGA2 multi-objective optimisation algorithm. The resulting system trials different intervention measures, using the intelligent option searching characteristics of the NSGAll, it then evaluates the costs associated with interventions and their benefits, in terms of risk reduction. This process is iterated until a Pareto Front, or "trade off" curve, is 
formed. An additional criterion of loss of life has been introduced as part of the overall objective function for the optimisation algorithm. Whilst this is useful for demonstrating the concepts and principles of the multiobjective algorithm, further work is required to make the life-loss estimates more robust.

The output from the system has the potential to provide a greater range of information to decision makers. The system is capable of outputting a set of trade off solutions which present a range of potential flood risk mitigation intervention strategies. Each strategy is optimal according to given criteria (costs, benefits, life loss) and presents information describing the most appropriate intervention measures to implement, when and where.

The application of the new decision support system on an area of the Thames Estuary demonstrates the benefits that multi-objective optimisation can bring to flood risk management. Multi-objective optimisation provides an approach for multiple criteria to be considered separately during the appraisal process and provides a set of optimal intervention strategies to help inform the decision making process. Insight into the problem characteristics is gained through this and a more informed decision can be made. The results show accepting one optimal solution without considering how it fits in and compares to other potential solutions can result in poor decisions. The use of multi-objective optimisation is therefore advantageous for decision makers especially in flood risk management with the large portfolio of mitigation actions available and the numerous criteria to assess them against.

Future work can potentially involve scaling up the methodology shown here to enable the solution of larger optimisation problems arising from different types of intervention options considered but also the increased number of (un)grouped linear levee sections analysed. Future work will also investigate the use of multiobjective optimisation techniques to determine flexible and adaptive flood risk strategies using the concepts of Real Options (Woodward et al., 2011).

\section{Acknowledgements}

The research work presented here was completed as part of the Knowledge Transfer Partnership project between HR Wallingford and the University of Exeter (KTP Programme No 6780), which is gratefully acknowledged. The research reported in this paper was also conducted as part of the work of the Flood Risk Management Research Consortium (FRMRC). The FRMRC is supported by Grant EP/F020511/1 from the Engineering and Physical Sciences Research Council (EPSRC), in partnership with the Department of Environment, Food and Rural Affairs/Environment Agency (Defra/EA) Joint Research Programme on Flood and Coastal Defence, United Kingdom Water Industry Research (UKWIR), the Office of Public Works (OPW) Dublin and the Northern Ireland Rivers Agency (DARDNI). This financial support is gratefully acknowledged.

\section{List of Symbols}

The following symbols are used in this paper:

$\begin{array}{ll}A & =\text { site access costs } \\ \alpha & =\text { number of components in the system } \\ B & =\text { benefits in terms of risk reduction } \\ C & =\text { total whole life system cost } \\ C_{m} & =\text { maintenance costs }\end{array}$




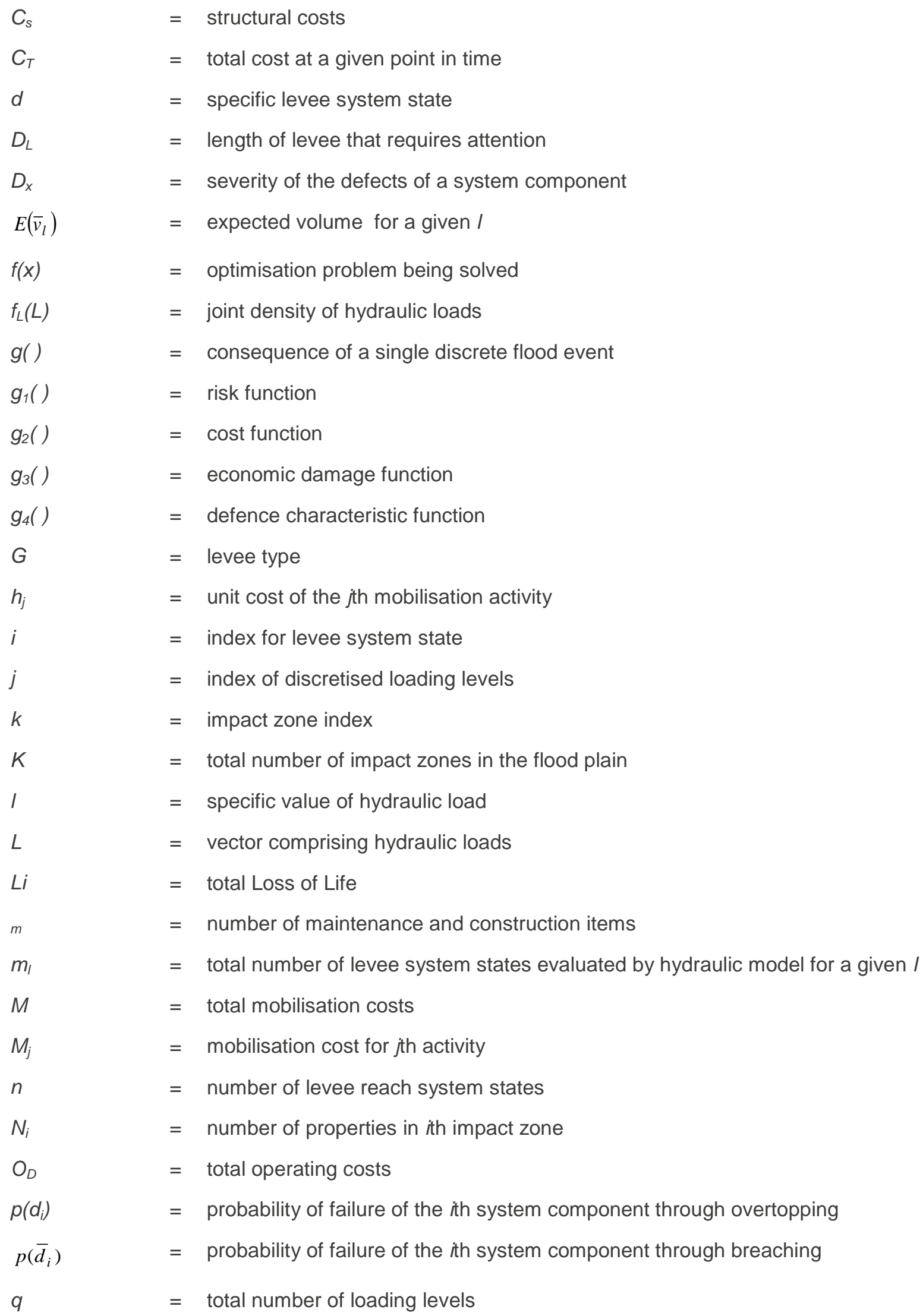




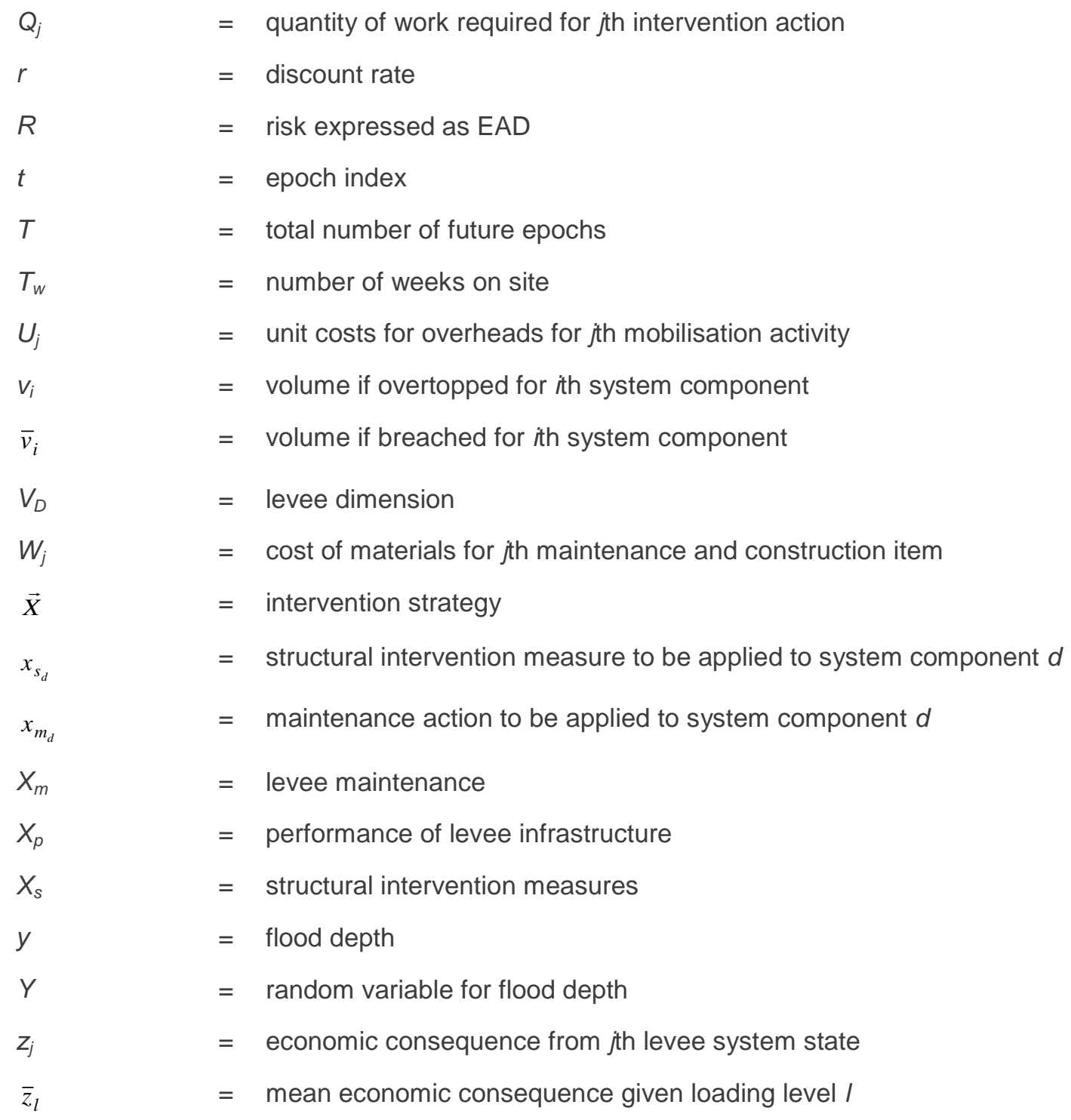

\section{References}

Aboelata, M. and Bowles, D. (2010) LIFESim: A tool for estimating and reducing life-loss resulting from dam and levee failure

Apel, H., Thieken, A., Merz, B. and Bloschl, G. (2004). "Flood risk assessment and associated uncertainty." Natural Hazards and Earth System Sciences 4: 295 - 308.

Behzadian, K., Kapelan, Z., Savic, D. and Ardeshir, A. (2009). "Stochastic Sampling Design using Multiobjective Genetic Algorithm and Adaptive Neural Networks." Environmental Modelling and Software 24(4): 530-541.

Coello, C. A. C. (1999). "A comprehensive Survey of Evolutionary-Based Multiobjective Optimization Techniques." Knowledge and Information Systems 1: 269 - 308. 
Deb, K., Agrawal, S., Pratap, A. and Meyarivan, T. (2000). "A fast elitist non-dominated sorting genetic algorithm for multi-objective optimisation: NSGA II." Parallel Problem Solving from Nature PPSN VI. Springer Berlin/Heidelberg.

Deb, K., Mohan, M. and Mishra, S. (2003) A Fast Multi-objective Evolutionary Algorithm for Finding WellSpread Pareto-Optimal Solutions

Deb, K., Pratap, A., Agarwal, A. and Meyarivan, T. (2002). "A fast and elitist multiobjective genetic algorithm: NSGAII." IEEE Transactions on Evolutionary Computation 6(2): 182-197.

Dorini, G., Jonkergouw, P., Kapelan, Z. and Savic, D. (2010). "SLOTS: Effective Algorithm for Sensor Placement in Water Distibution Systems." Journal of Water Resources Planning and Management 136(6).

Duan, Q., Gupta, V. and Sorooshian, S. (1993). "Shuffled Complex Evolution Approach for Effective and Efficient Global Minimization." Journal of Optimization Theory and Applications 76(3): 501 - 521.

Environment Agency (2009a) Guidance on Capital and Maintenance costs and different asset types for whole life costing. Outcome MSF 9.2 from PAMS (Performance-based Asset Management System)

Environment Agency (2009b) Guidance on Determining Asset Deterioration and the Use of Condition Grade Deterioration Curves SR2

Environment Agency (2009c) Managing flood risk through London and the Thames estuary: Strategic Environmental Assessment, Environmental Report Summary.

Environment Agency (2009d) Thames Estuary 2100. Managing flood risk through London and the Thames Estuary. TE2100 Plan: Consultation Document

Fonseca, C. and Fleming, P. (1998). "Multiobjective optimisation and multiple constraint handling with evolutionary algorithms I: A unifired formulation." Systems, Man and Cybernetics 28(1).

Goldberg, D. E. (1989). Genetic Algorithms in Search, Optimization and Machine Learning. Reading, Mass., Addison Wesley Longman, Inc.

Gouldby, B., Sayers, P., Mulet-Marti, J., Hassan, M. and Benwell, D. (2008). "A methodology for regionalscale flood risk assessment." Water Management 161(3): 169-182.

Hall, J., Dawson, R., Sayers, P., Rosu, C., Chatterton, J. and Deakin, R. (2003). "A methodology for nationalscale flood risk assessment." Proceedings of the Institution of Civil Engineers, Water and Maritime Engineering 156(3): 235 - 247.

Hawkes, P. J., Gouldby, B. P., Tawn, J. A. and Owen, M. W. (2002). "The joint probability of waves and water levels in coastal engineering design." Journal of Hydraulic Research 40(3): 241-251.

Kapelan, Z., Savic, D. and Walters, G. (2003). "Multiobjective Sampling Design for Water Distribution Model Calibration." ASCE Journal of Water Resources Planning and Management 129(6): 466-479.

Lamb, R., Keef, C., Tawn, J., Laeger, S., Meadowcroft, I., Surendran, S., Dunning, P. and Batstone, C. (2010). "A new method to assess the risk of local and widespread flooding on rivers and coasts." Journal of Flood Risk Management 3(4): 323-336.

Langdon, D. (2010). SPON'S - Civil Engineering and Highway Works Price Book 2010, Spon Press.

Lhomme, J., Sayers, P., Gouldby, B., Samuels, P., Wills, M. and Mulet-Marti, J. (2008). Recent development and application of a rapid flood spreading method. Flood Risk 2008, Oxford. 
Lumbroso, D., Di Mauro, M. and Ramsbottom, D. (2008). Recent developments in loss of life modelling for flood defence and dam break risk assessments. 43rd Defra Flood and Coastal Management Conference, Manchester University.

Lund, J. (2002). "Floodplain Planning with Risk-based Optimization." Journal of Water Resources Planning and Management 127(3).

Phillips, T. (2008) Unpublished note on the Cost estimation model for WP4.4 in FRMRC1: Time dependent defence reliability analysis and option searching University of Newcastle

Samuels, P., Morris, M., Sayers, P., Creutin, J., Kortenhaus, A., Klijn, F., Mosselman, E., Van Os, A. and Schanze, J. (2009). Advances in flood risk management from the FLOODsite project. Flood Risk Management: Research and Practice. P. Samuels, S. Huntington, W. Allsop and J. Harrop, Taylor and Francis Group, London.

Savic, D. and Walters, G. (1997). "Genetic Algorithms for least-cost design of water distribution networks." Journal of Water Resources Planning and Management 123(2): 67-77.

Schanze, J. (2006). Flood Risk Management - A basic framework. Flood risk management: Hazards, vulnerability and mitigation measures, NATO Science Series IV: Earth and Environmental Sciences, Volume 67, Part 1, 1-20. 67.

Schultz, M., Gouldby, B., Simm, J. and Wibowo, J. (2010) Beyond the Factor of Saftey: Developing Fragility Curves to Characterize System Reliability

Simm, J., Gouldby, B., Sayers, P., Flikweert, J., Wersching, S. and Bramley, M. (2009). Representing fragility of flood and coastal defences: Getting into the detail. Flood Risk Management: Research and Practice. P. Samuels, S. Huntington, W. Allsop and J. Harrop, Taylor and Francis Group, London, UK.

Srinivas, N. and Deb, K. (1994). "Multiobjective Optimization using nondominated sorting in genetic algorithms." Evolutionary Computation 2: 221 - 248.

USACE (1996) Risk-based Analysis for Flood Damage Reduction studies Engineer Manual EM 1110-2-1619

Valdes, J. J. and Barton, A. J. (2007). Visualizing high dimensional objective spaces for multi-objective optimization: A virtual reality approach. Evolutionary Computation, 2007. CEC 2007. IEEE Congress on.

Voortman, H. and Vrijling, J. (2003). Time-dependent reliability analysis of coastal flood defence systems. Proceedings European Safety and Reliability conference (ESREL).

Vorogushyn, S., Merz, B. and Apel, H. (2009). "Development of dike fragility curves for piping and microinstability breach mechanisms." Nat. Hazards Earth Syst. Sci. 9(4): 1383-1401.

Ward, P. J., de Moel, H. and Aerts, J. C. J. H. (2011). "How are flood risk estimates affected by the choice of return-periods?" Nat. Hazards Earth Syst. Sci. 11(12): 3181-3195.

Weickgenannt, M., Kapelan, Z., Blokker, M. and Savic, D. (2010). "Risk-Based Sensor Placement for Contaminant Detection in Water Distibution Systems." Journal of Water Resources Planning and Management 136(6).

Woodward, M., Gouldby, B., Kapelan, Z., Khu, S. T. and Townend, I. (2011). "Real Options in flood risk management decision making." Journal of Flood Risk Management 4(4): 339-349. 
Zitzler, E., Laumanns, M. and Thiele, L. (2001). SPEA2: Improving the strength pareto evolutionary algorithm, Eidgenössische Technische Hochschule Zürich (ETH), Institut für Technische Informatik und Kommunikationsnetze (TIK).

\section{List of Figures}

Figure 1 Conceptual illustration of the modelled system

Figure 2 Algorithm describing the main stages of the NSGAll

Figure 3 Probability damage curve for forty and seven RPs

Figure 4 A simplified flowchart of the risk analysis methodology compared against the modified version

Figure 5 Component of the automated costing methodology

Figure 6 Flowchart to calculate the quantity of work required in the cost model for a type 2 levee as defined in the risk analysis model

Figure 7 Progression of the solutions (squares represent Pareto Front, circular points represent remaining solutions in the current NSGA2 population) across the generations

Figure 8 The Pareto Front for the final generation including the solutions with the highest NPV and BCR Figure 9 Flood depth realisation for a 100year loading level on the flood area of interest

Figure 10 Pareto Front for final generation according to three objectives including the solutions with the highest NPV and BCR 


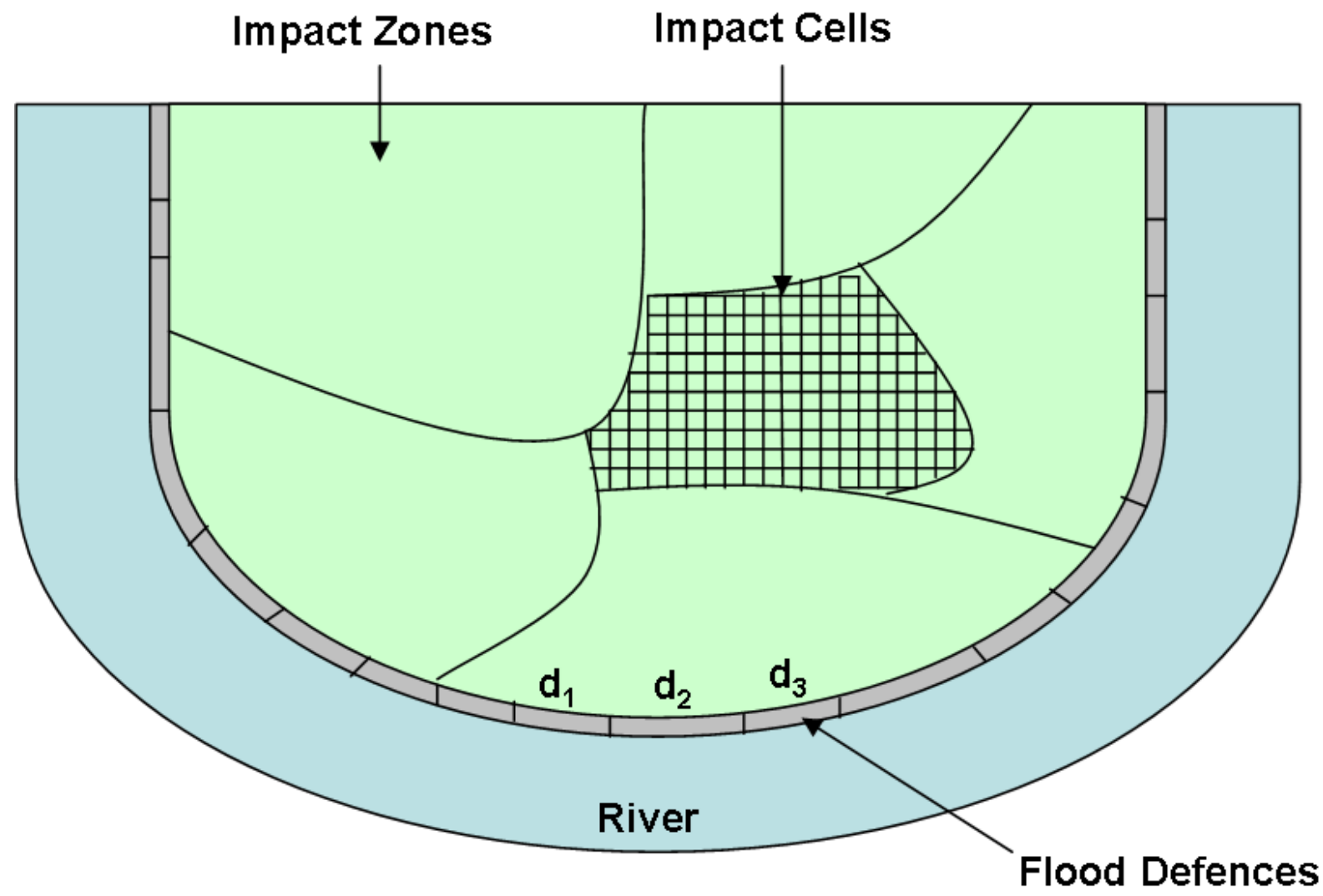

Figure 1: Conceptual illustration of the modelled system 


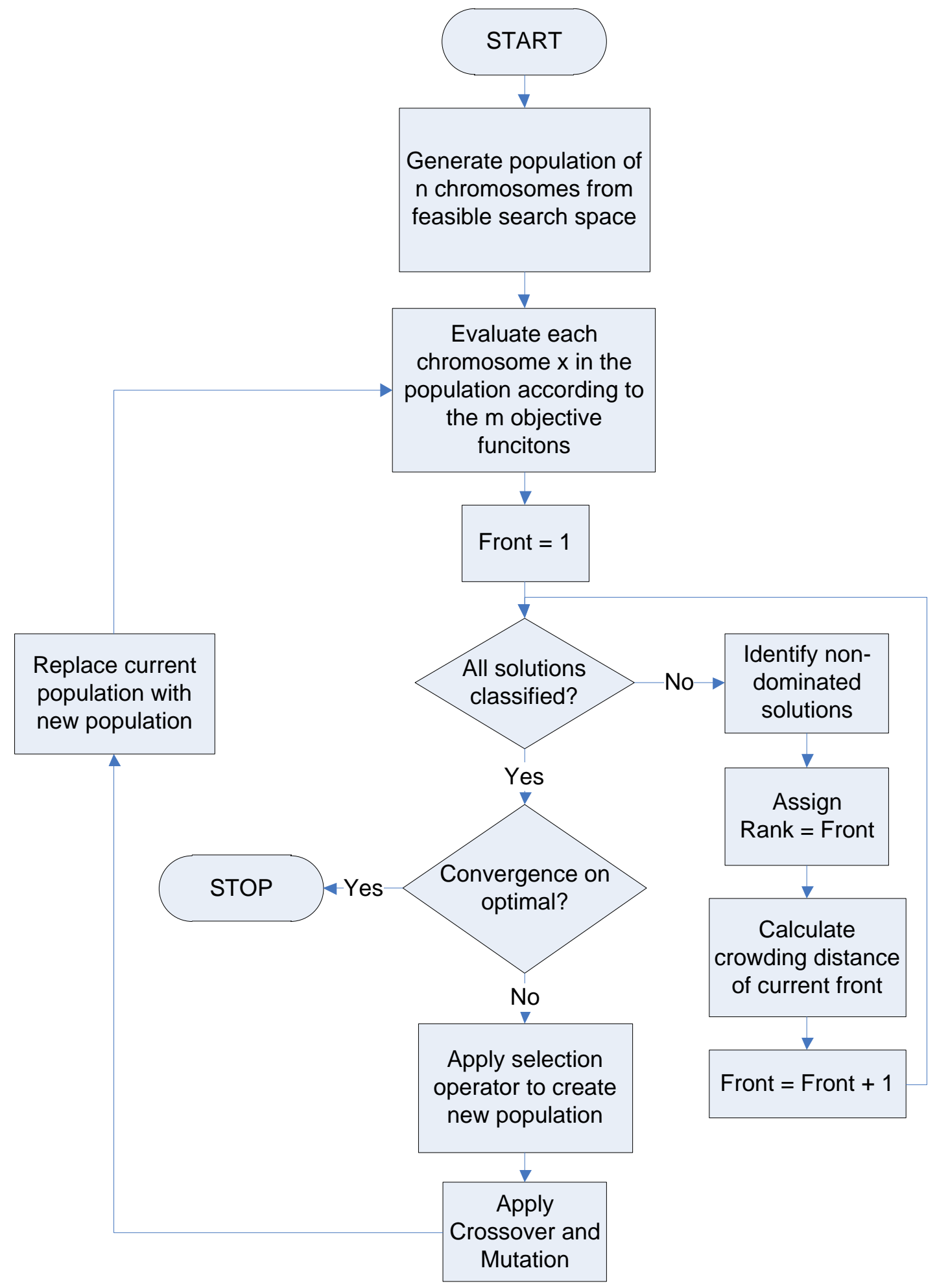

Figure 2: Algorithm describing the main stages of the NSGAll 


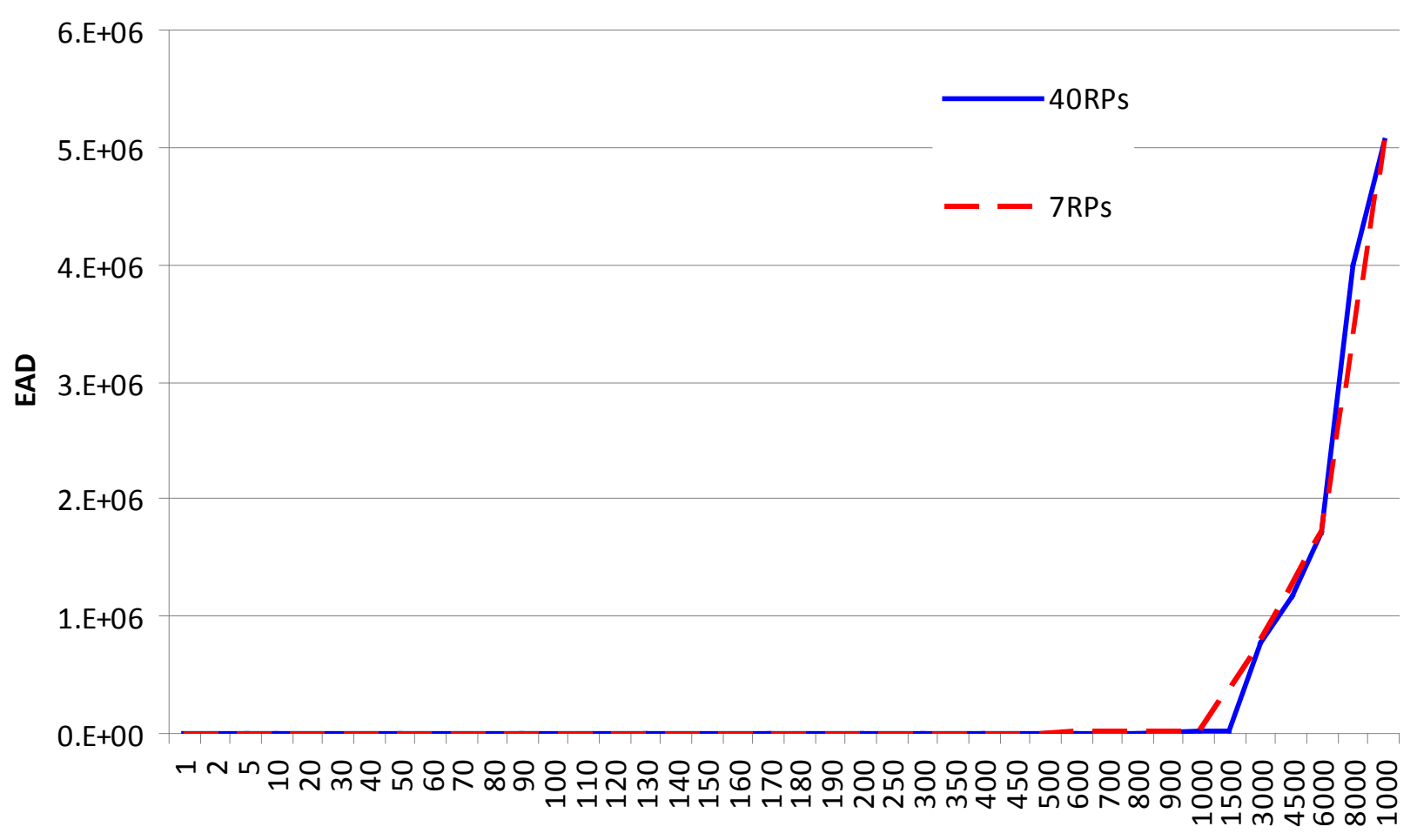

RPs

Figure 3: Probability damage curve for forty and seven RPs 
Brief flowchart of risk analysis tool before modifications

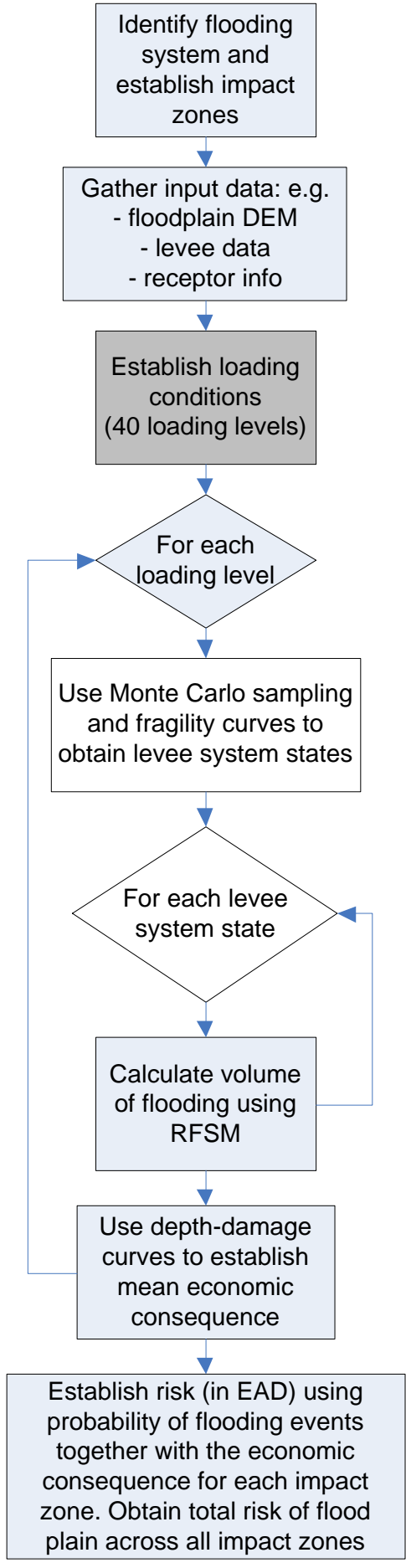

Brief flowchart of risk analysis tool with modifications

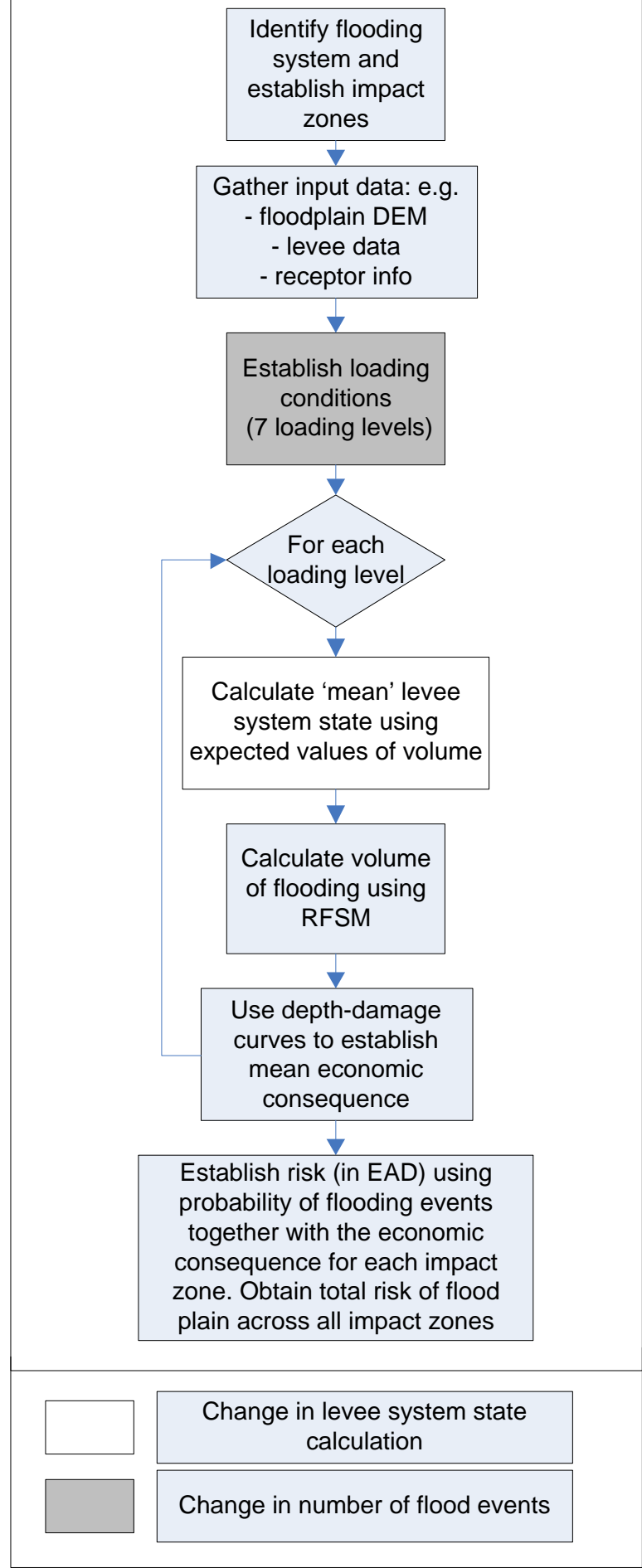

Figure 4: A simplified flowchart of the risk analysis methodology compared against the modified version 


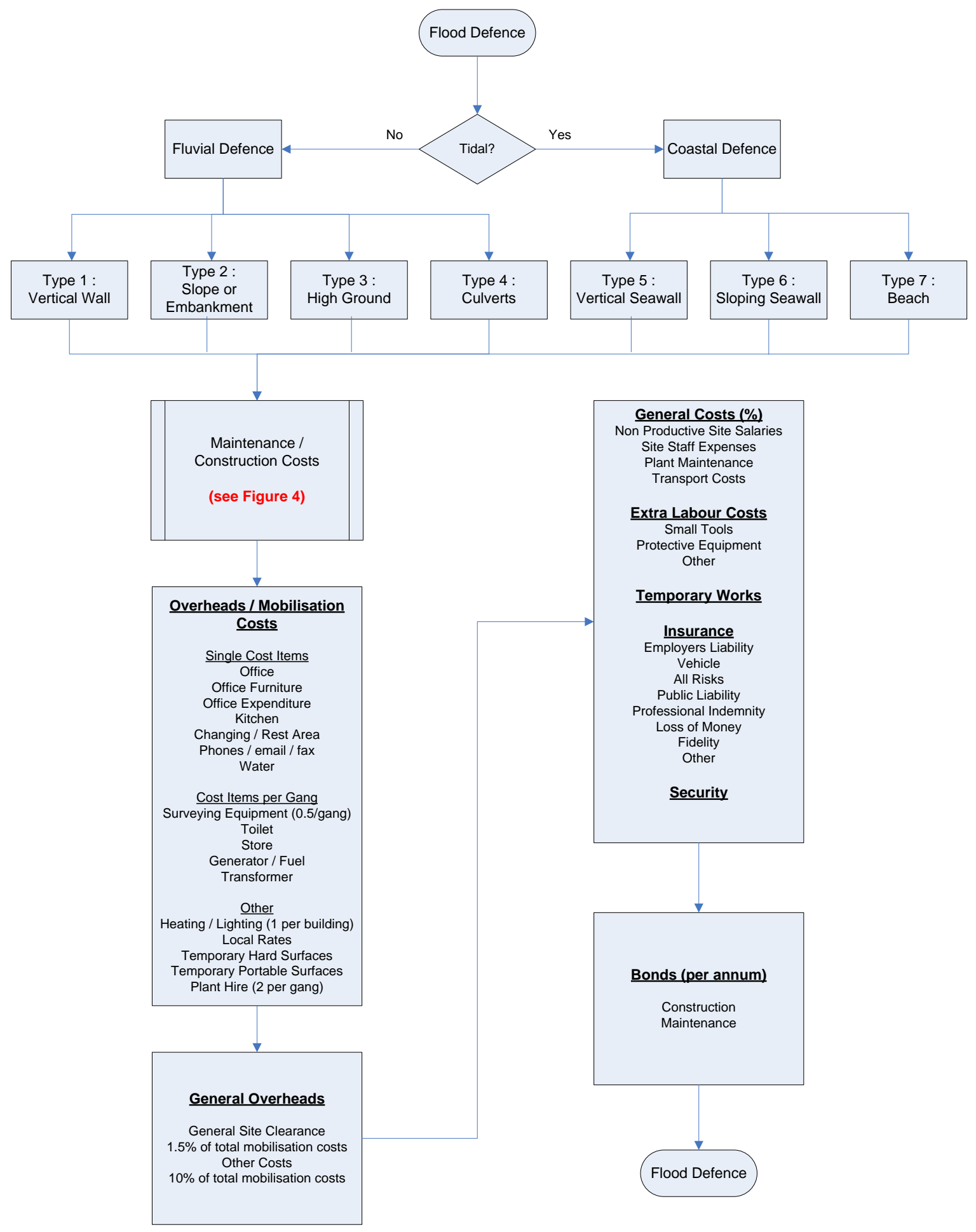

Figure 5: Component of the automated costing methodology 


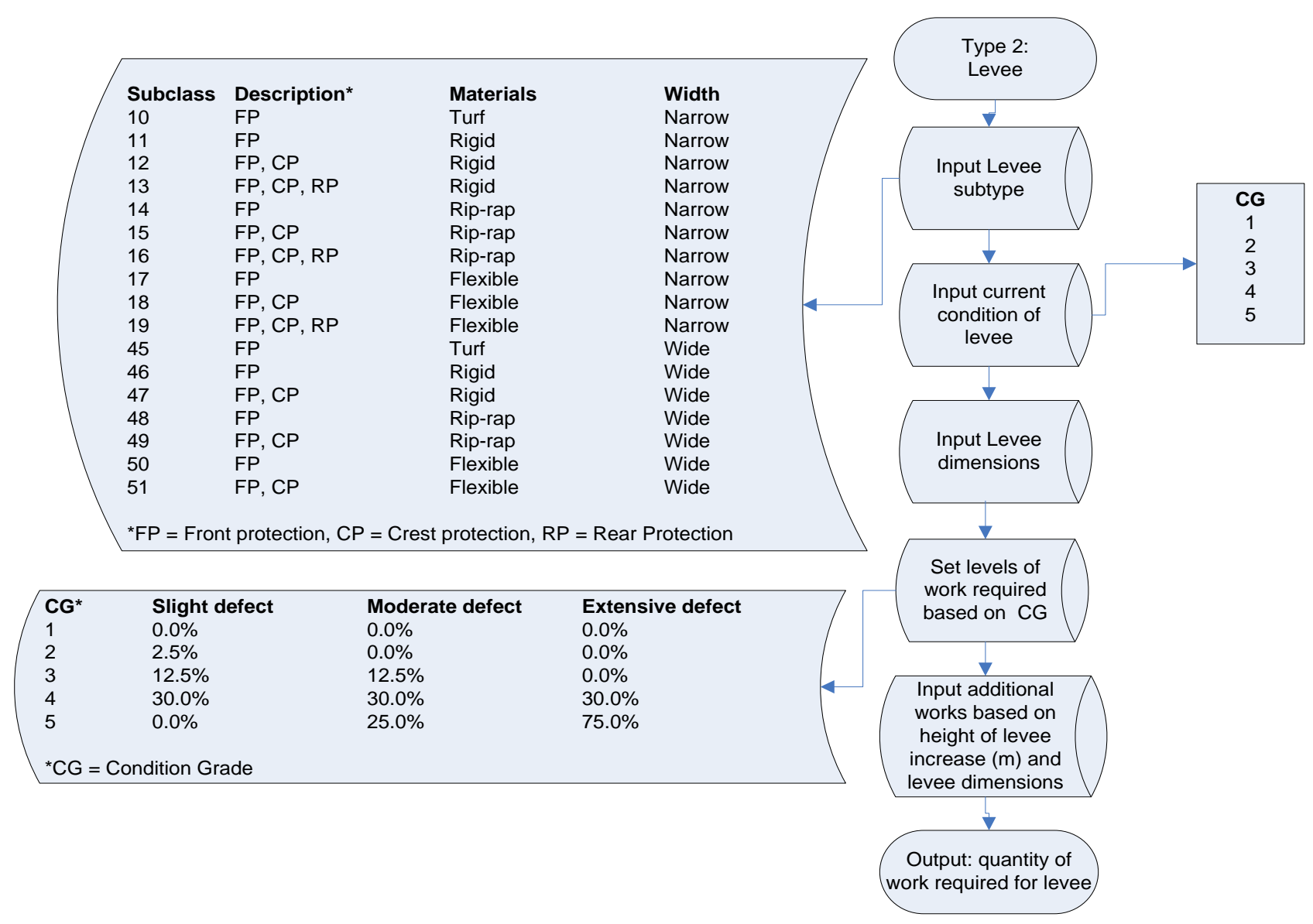

Figure 6: Flowchart to calculate the quantity of work required in the cost model for a type 2 levee as defined in the risk analysis model 

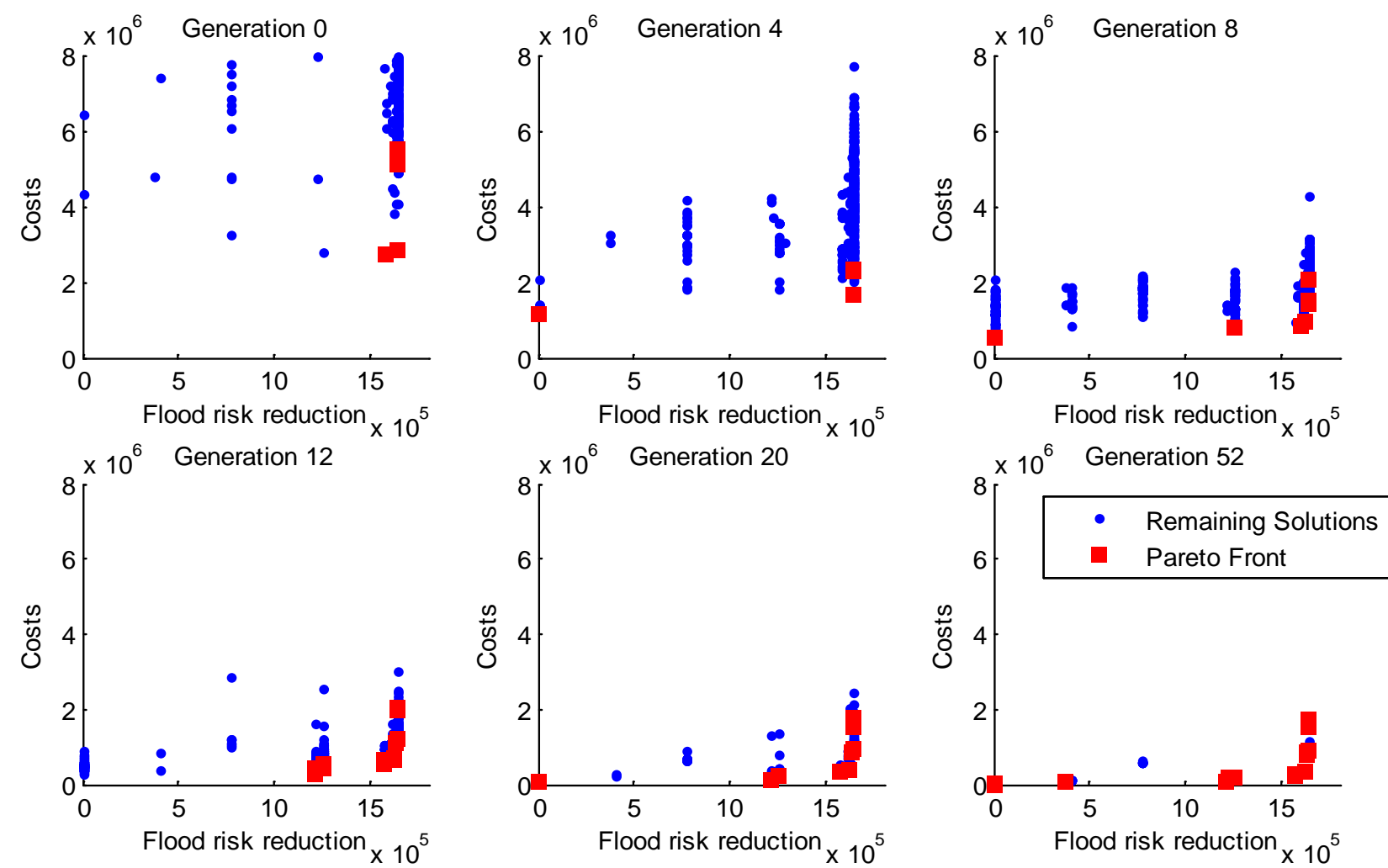

Figure 7: Progression of the solutions (squares represent Pareto Front, circular points represent remaining solutions in the current NSGA2 population) across the generations 


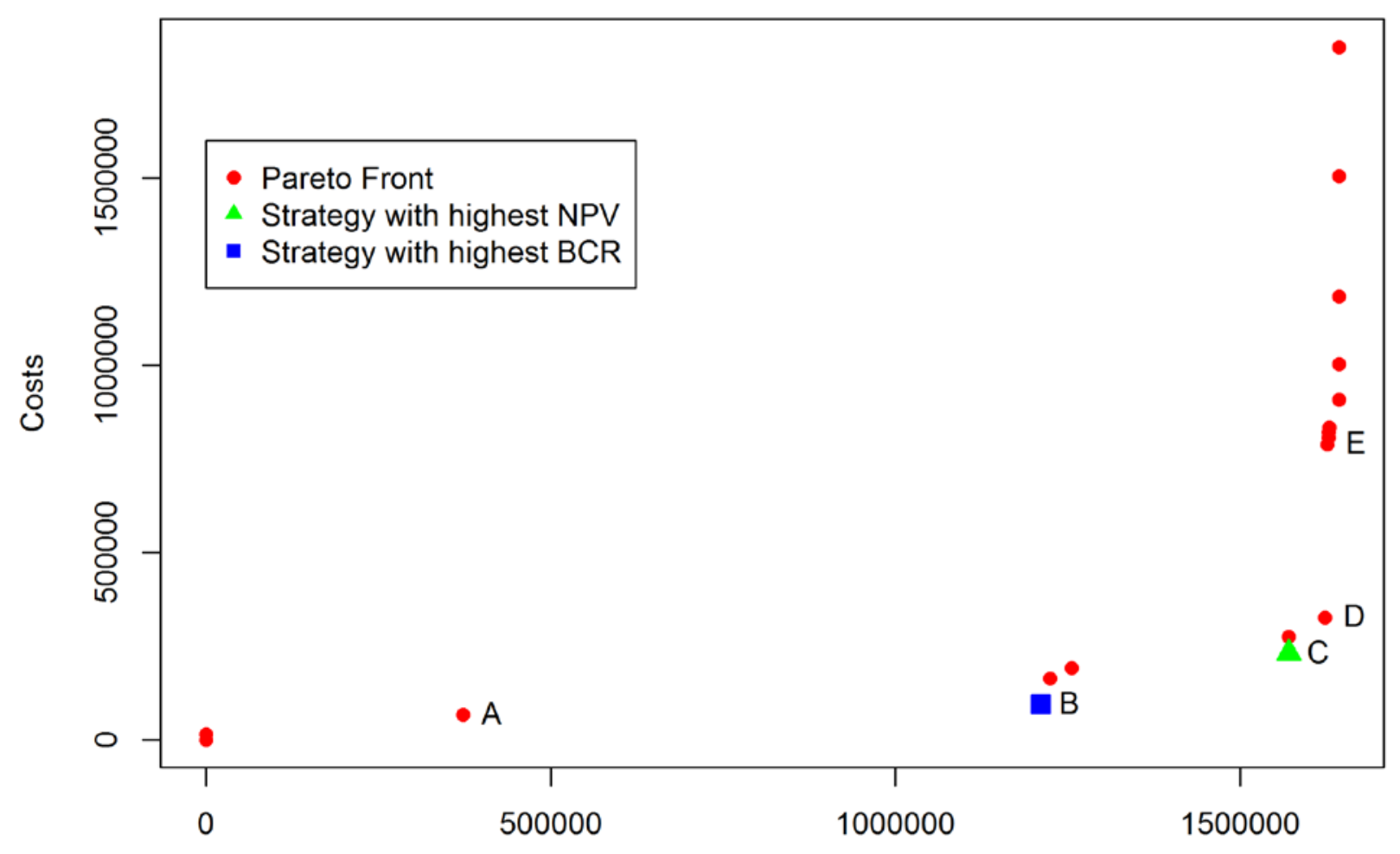

Flood risk reduction

Figure 8: The Pareto Front for the final generation including the solutions with the highest NPV and BCR 


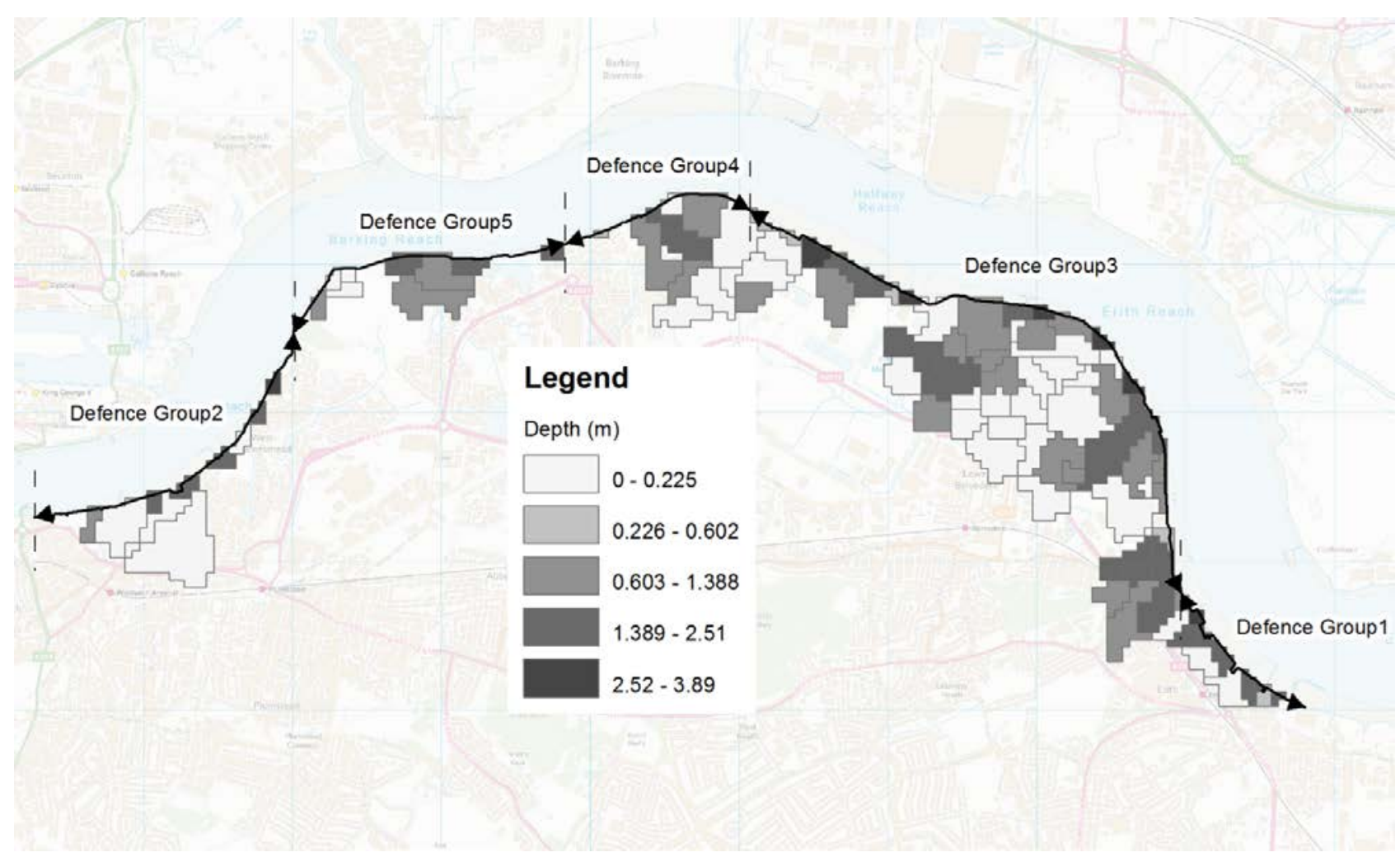

Figure 9: Flood depth realisation for a 100 year loading level on the flood area of interest

Source: Contains Ordnance Survey data @ Crown copyright and database rights 2011 

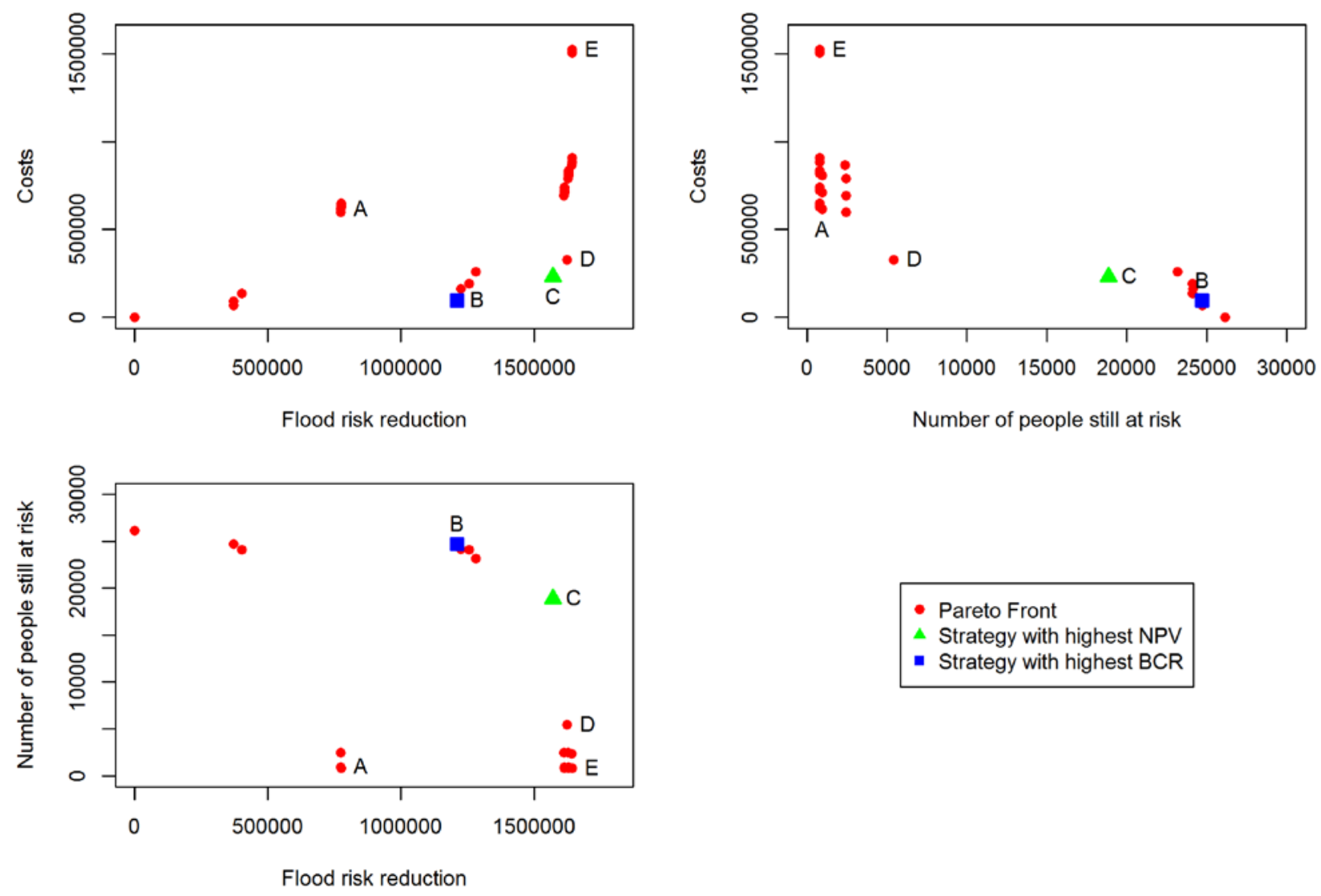

- Pareto Front

- Strategy with highest NPV

- Strategy with highest BCR

Figure 10: Pareto Front for final generation according to three objectives including the solutions with the highest NPV and BCR 


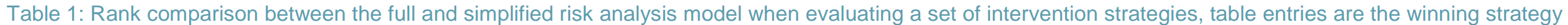
(ie less EAD)

\begin{tabular}{|c|c|c|c|c|c|c|c|c|c|c|c|c|c|c|c|c|c|c|}
\hline EAD (£) & & 36,400 & 148,300 & 142,600 & 148,900 & 60,700 & 70,700 & 26,000 & 3,900 & 2,000 & 73,100 & 128,800 & 2,200 & 46,900 & 71,100 & 60,800 & \multirow{2}{*}{\multicolumn{2}{|c|}{$\begin{array}{l}\text { Simplified } \\
\text { risk analysis }\end{array}$}} \\
\hline \multicolumn{2}{|l|}{ Strategy } & 1 & 2 & 3 & 4 & 5 & 6 & 7 & 8 & 9 & 10 & 11 & 12 & 13 & 14 & 15 & & \\
\hline 33,700 & 1 & 1 & 1 & 1 & 1 & 1 & 1 & 7 & 8 & 9 & 1 & 1 & 12 & 1 & 1 & 1 & 1 & 36,400 \\
\hline 145,800 & 2 & 1 & 2 & 3 & 2 & 5 & 6 & 7 & 8 & 9 & 10 & 11 & 12 & 13 & 14 & 15 & 2 & 148,300 \\
\hline 141,300 & 3 & 1 & 3 & 3 & 3 & 5 & 6 & 7 & 8 & 9 & 10 & 11 & 12 & 13 & 14 & 15 & 3 & 142,600 \\
\hline 149,000 & 4 & 1 & 2 & 3 & 4 & 5 & 6 & 7 & 8 & 9 & 10 & 11 & 12 & 13 & 14 & 15 & 4 & 148,900 \\
\hline 60,400 & 5 & 1 & 5 & 5 & 5 & 5 & 5 & 7 & 8 & 9 & 5 & 5 & 12 & 13 & 5 & 5 & 5 & 60,700 \\
\hline 70,700 & 6 & 1 & 6 & 6 & 6 & 5 & 6 & 7 & 8 & 9 & 6 & 6 & 12 & 13 & 6 & 15 & 6 & 70,700 \\
\hline 26,500 & 7 & 7 & 7 & 7 & 7 & 7 & 7 & 7 & 8 & 9 & 7 & 7 & 12 & 7 & 7 & 7 & 7 & 26,000 \\
\hline 4,700 & 8 & 8 & 8 & 8 & 8 & 8 & 8 & 8 & 8 & 9 & 8 & 8 & 12 & 8 & 8 & 8 & 8 & 3,900 \\
\hline 1,200 & 9 & 9 & 9 & 9 & 9 & 9 & 9 & 9 & 9 & 9 & 9 & 9 & 9 & 9 & 9 & 9 & 9 & 2,000 \\
\hline 72,200 & 10 & 1 & 10 & 10 & 10 & 5 & 6 & 7 & 8 & 9 & 10 & 10 & 12 & 13 & 14 & 15 & 10 & 73,100 \\
\hline 125,900 & 11 & 1 & 11 & 11 & 11 & 5 & 6 & 7 & 8 & 9 & 10 & 11 & 12 & 13 & 14 & 15 & 11 & 128,800 \\
\hline 1,900 & 12 & 12 & 12 & 12 & 12 & 12 & 12 & 12 & 12 & 9 & 12 & 12 & 12 & 12 & 12 & 12 & 12 & 2,200 \\
\hline 43,300 & 13 & 1 & 13 & 13 & 13 & 13 & 13 & 7 & 8 & 9 & 13 & 13 & 12 & 13 & 13 & 13 & 13 & 46,900 \\
\hline 70,800 & 14 & 1 & 14 & 14 & 14 & 5 & 14 & 7 & 8 & 9 & 14 & 14 & 12 & 13 & 14 & 15 & 14 & 71,100 \\
\hline 60,100 & 15 & 1 & 15 & 15 & 15 & 15 & 15 & 7 & 8 & 9 & 15 & 15 & 12 & 13 & 15 & 15 & 15 & 60,800 \\
\hline \multirow{2}{*}{\multicolumn{2}{|c|}{$\begin{array}{l}\text { Full risk } \\
\text { analysis }\end{array}$}} & 1 & 2 & 3 & 4 & 5 & 6 & 7 & 8 & 9 & 10 & 11 & 12 & 13 & 14 & 15 & \multicolumn{2}{|c|}{ Strategy } \\
\hline & & 33,700 & 145,800 & 141,300 & 149,000 & 60,400 & 70,700 & 26,500 & 4,700 & 1,200 & 72,200 & 125,900 & 1,900 & 43,300 & 70,800 & 60,100 & \multicolumn{2}{|c|}{ EAD $(£)$} \\
\hline
\end{tabular}


Table 2: Percentage of intervention measures which achieve the same rank ordering when analysed against the full and simplified risk analysis tool for five different tests

\begin{tabular}{|l|r|}
\hline Test Number & $\begin{array}{r}\text { Number of interventions following same pattern for the } \\
\text { full and simplified risk analysis tool (\%) }\end{array}$ \\
\hline Test 1 & 97.82 \\
\hline Test 2 & 98.26 \\
\hline Test 3 & 97.77 \\
\hline Test 4 & 97.88 \\
\hline Test 5 & 98.13 \\
\hline Average & $\mathbf{9 7 . 9 7}$ \\
\hline
\end{tabular}

Table 3: The benefits, costs, NPV, BCR and intervention measures for each of the strategies labelled in Figure 8

\begin{tabular}{|c|c|c|c|c|c|c|c|c|}
\hline \multirow[b]{2}{*}{ Strategy } & \multirow{2}{*}{$\begin{array}{l}\text { Benefit } \\
£ 000 \text { 's }\end{array}$} & \multirow{2}{*}{$\begin{array}{l}\text { Cost } \\
£ 000 \text { 's }\end{array}$} & \multirow{2}{*}{$\begin{array}{l}\text { NPV } \\
E \text { 's }\end{array}$} & \multirow[b]{2}{*}{ BCR } & \multicolumn{2}{|c|}{ Time step 1} & \multicolumn{2}{|c|}{ Time step 2} \\
\hline & & & & & G1 & G3 & G1 & G3 \\
\hline A & 372.5 & 67.8 & 304.7 & 5.49 & 0 & 0 & $\begin{array}{l}\text { Low } \\
\text { Main }\end{array}$ & 0 \\
\hline B & 1211.1 & 95.8 & 1115.3 & 12.64 & 0 & $\begin{array}{l}\text { Low } \\
\text { Main }\end{array}$ & 0 & 0 \\
\hline C & 1570.8 & 231.5 & 1339.3 & 6.78 & 0 & $\begin{array}{l}\text { Low } \\
\text { Main }\end{array}$ & 0 & $\begin{array}{l}\text { Med } \\
\text { Main }\end{array}$ \\
\hline D & 1622.8 & 327.3 & 1295.5 & 5.70 & 0 & $\begin{array}{l}\text { Med } \\
\text { Main }\end{array}$ & 0 & $\begin{array}{l}\text { Med } \\
\text { Main }\end{array}$ \\
\hline$E$ & 1627.1 & 789.2 & 837.9 & 2.06 & 0 & $\begin{array}{l}\text { Med } \\
\text { Main }\end{array}$ & $\begin{array}{l}0.33 m \\
R C L\end{array}$ & 0 \\
\hline
\end{tabular}

Note: $\quad$ Main = apply maintenance (low = low deterioration rate, med = medium deterioration rate) $R C L=$ raise crest level $(m)$ 
Table 4: The benefits, costs, NPV, BCR and intervention measures for each of the intervention strategies labelled in Figure 10

\begin{tabular}{|c|c|c|c|c|c|c|c|c|c|}
\hline \multirow[b]{2}{*}{ Strategy } & \multirow{2}{*}{$\begin{array}{l}\text { Benefit } \\
£ 000 \text { 's }\end{array}$} & \multirow{2}{*}{$\begin{array}{l}\text { Cost } \\
£ 000 \text { 's }\end{array}$} & \multirow{2}{*}{$\begin{array}{l}\text { NPV } \\
£ \text { 's }\end{array}$} & \multirow[b]{2}{*}{ BCR } & \multirow{2}{*}{$\begin{array}{l}\text { Number of } \\
\text { properties }\end{array}$} & \multicolumn{2}{|c|}{ Time step 1} & \multicolumn{2}{|c|}{ Time step 2} \\
\hline & & & & & & G1 & G3 & G1 & G3 \\
\hline A & 774.8 & 67.8 & 304.7 & 5.49 & 940 & 0 & 0 & $\begin{array}{l}0.66 \mathrm{~m} \\
\mathrm{RCL}\end{array}$ & 0 \\
\hline B & 1211.1 & 95.8 & 1115.3 & 12.64 & 24,710 & 0 & $\begin{array}{l}\text { Low } \\
\text { Main }\end{array}$ & 0 & 0 \\
\hline C & 1570.8 & 231.5 & 1339.3 & 6.78 & 18,860 & 0 & $\begin{array}{l}\text { Low } \\
\text { Main }\end{array}$ & 0 & $\begin{array}{l}\text { Med } \\
\text { Main }\end{array}$ \\
\hline D & 1622.8 & 327.3 & 1295.5 & 5.70 & 5,435 & 0 & $\begin{array}{l}\text { Med } \\
\text { Main }\end{array}$ & 0 & $\begin{array}{l}\text { Med } \\
\text { Main }\end{array}$ \\
\hline$E$ & 1643.4 & 1521.9 & 121.5 & 10.80 & 785 & $\begin{array}{l}1.33 m \\
R C L\end{array}$ & 0 & $\begin{array}{l}0.66 \mathrm{~m} \\
\mathrm{RCL}\end{array}$ & 0 \\
\hline
\end{tabular}

Note: $\quad$ Main = apply maintenance (low = low deterioration rate, med = medium deterioration rate) $R C L=$ raise crest level $(m)$ 